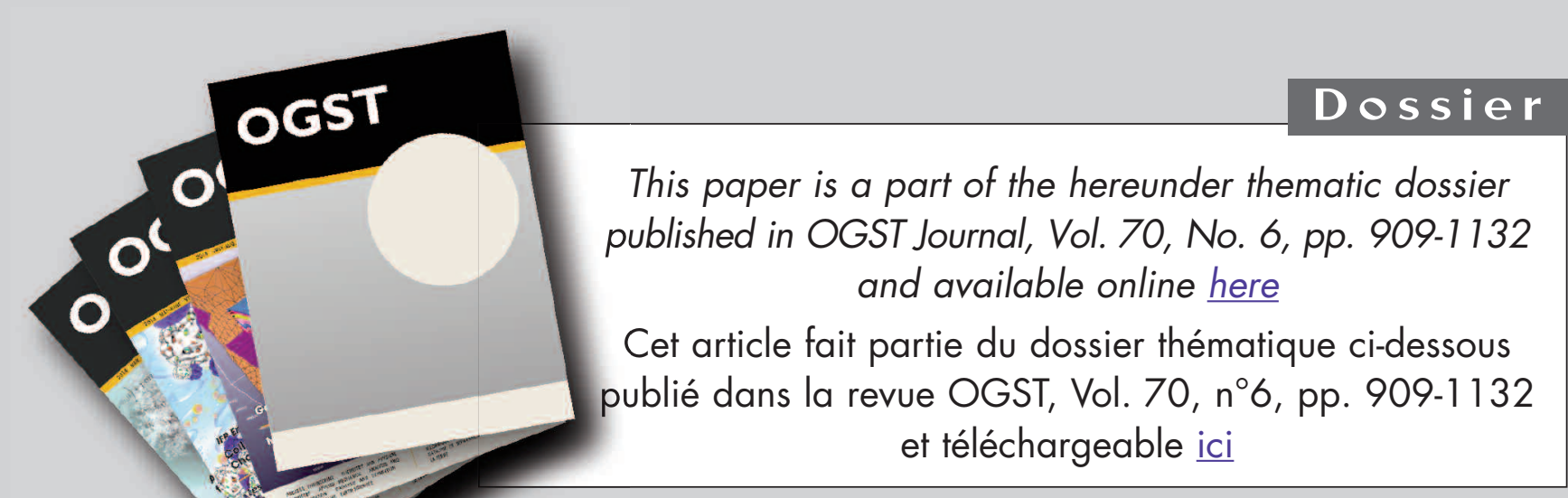

Oil \& Gas Science and Technology - Rev. IFP Energies nouvelles, Vol. 70 (2015), No. 6, pp. 909-1132

Copyright (C) 2015, IFP Energies nouvelles

909 > Editorial - Enhanced Oil Recovery (EOR), Asphaltenes and Hydrates Éditorial - EOR «récupération assistée du pétrole», Asphaltènes et Hydrates D. Langevin and F. Baudin

\section{ENHANCED OIL RECOVERY (EOR)}

917 > HP-HT Drilling Mud Based on Environmently-Friendly Fluorinated Chemicals Boues de forage HP/HT à base de composés fluorés respectueux de I'environnement

I. Henaut, D. Pasquier, S. Rovinetti and B. Espagne

931 > Effective Viscosity in Porous Media and Applicable Limitations for Polymer Flooding of an Associative Polymer

Viscosité effective dans des médias poreux et limites d'application de l'injection de polymères associatifs

P. Zhang, Y. Wang, Y. Yang, W. Chen and S. Bai

$941>$ Dynamic Gelation of HPAM/Cr(III) under Shear in an Agitator and Porous Media Gélification dynamique de HPAM/Cr(III) sous cisaillement dans un agitateur et en milieu poreux

Y. Haiyang, W. Yefei, Z. Jian, L. Peng and S. Shenglong

$951>$ Computer Modeling of the Displacement Behavior of Carbon Dioxide in Undersaturated Oil Reservoirs

Modélisation par ordinateur du comportement de déplacement du dioxyde de carbone dans des réservoirs d'huile non saturés

B. Ju, Y.S. Wu and J. Qin

$967>$ Predicting CO, Minimum Miscibility Pressure (MMP) Using Alternating Conditional Expectation (ACE) Algorithm

Prédiction de la pression miscibilité minimum (MMP) du CO en utilisant un algorithme basé sur l'ACE (Alternating Conditional Expectation)

0 . Alomair, A. Malallah, A. Elsharkawy and M. Iqbal

983 > Towards the Development of Bitumen Carbonates: An Integrated Analysis of Grosmont Steam Pilots

Vers le développement des carbonates bitumineux : une analyse intégrée des pilotes vapeur de Grosmont

C.C. Ezeuko, J. Wang, M.S. Kallos and I.D. Gates

1007> A Novel Model of Foam Flooding Considering Multi-Factors for Enhancing Oil Recovery

Un nouveau modèle d'injection de mousse considérant de multiples facteurs afin d'améliorer la récupération de pétrole

J. Wang, H. Liu, H. Zhang, G. Zhang, P. Liu and K. Sepehrnoori
1025> Testing of Snorre Field Foam Assisted Water Alternating Gas (FAWAG) Performance in New Foam Screening Model

Vérification des performances de la méthode FAWAG (Foam Assisted Water Alternating Gas) sur le champ de Snorre, en Norvège, avec un nouveau modèle de sélection des mousses

P. Spirov and S. Rudyk

\section{ASPHALTENES}

1035> Structural Study of Asphaltenes from Iranian Heavy Crude Oil Étude structurale d'asphaltènes de pétrole brut lourd iranien L. Davarpanah, F. Vahabzadeh and A. Dermanaki

$1051>$ Experimental Study and Mathematical Modeling of Asphaltene Deposition Mechanism in Core Samples

Étude expérimentale et modélisation mathématique du mécanisme de déposition d'asphaltène dans des carottes de forage

T. Jafari Behbahani, C. Ghotbi, V. Taghikhani and A. Shahrabadi

1075> Prediction of the Gas Injection Effect on the Asphaltene Phase Envelope Prévision Prévision de l'effet d'injection de gaz sur l'enveloppe de phase des asphaltènes P. Bahrami, R. Kharrat, S. Mahdavi and H. Firoozinia

\section{HYDRATES}

1087> Methane Hydrate Formation and Dissociation in the Presence of Silica Sand and Bentonite Clay

Formation et dissociation d'hydrates de méthane en présence de sable de silice et d'argile de bentonite

V. Kumar Saw, G. Udayabhanu, A. Mandal and S. Laik

$1101>$ Prediction of Mass Flow Rate in Supersonic Natural Gas Processing Prédiction du débit massique dans les applications de traitement supersonique du gaz naturel

C. Wen, X. Cao, Y. Yang and Y. Feng

$1111>$ Experimental Study on Hydrate Induction Time of Gas-Saturated Water-in-Oil Emulsion using a High-Pressure Flow Loop

Étude expérimentale sur le temps d'induction d'hydrate d'une émulsion eau-enhuile saturée en gaz en utilisant une boucle à circulation sous haute pression X.F. Lv, B.H. Shi, Y. Wang, Y.X. Tang, L.Y. Wang and J. Gong

1125> Hollow Silica: A Novel Material for Methane Storage La silice creuse : un nouveau matériau pour le stockage de méthane V.D. Chari, P.S.R. Prasad and S.R. Murthy 


\title{
Prediction of Mass Flow Rate in Supersonic Natural Gas Processing
}

\author{
Chuang Wen ${ }^{1,3}$, Xuewen $\mathrm{Cao}^{1 *}$, Yan Yang ${ }^{2}$ and Yuqing Feng ${ }^{3}$ \\ ${ }^{1}$ College of Pipeline and Civil Engineering, China University of Petroleum, 66 Changiiang West Road, Huangdao District, \\ Qingdao, 266580 - China \\ ${ }^{2}$ School of Petroleum Engineering, Changzhou University, Zhonglou District, Changzhou, Jiangsu, 213016 - China \\ ${ }^{3}$ CSIRO Computational Informatics, Clayłon, Victoria 3169 - Australia \\ e-mail: wenchuang2008@gmail.com - caoxw@upc.edu.cn - flyloveyang@gmail.com - yuqing.feng@csiro.au \\ * Corresponding author
}

\begin{abstract}
Résumé - Prédiction du débit massique dans les applications de traitement supersonique du gaz naturel - Le débit massique volumique de gaz naturel à travers un séparateur supersonique a été calculé numériquement en utilisant plusieurs équations d'état cubiques. Les résultats numériques indiquent que les coefficients de compressibilité et les coefficients de chaleur spécifique calculés avec les modèles de gaz réels diffèrent remarquablement des résultats issus de la loi des gaz parfaits pour une pression d'entrée élevée. Parallèlement, les calculs de débit massique effectués avec les modèles de gaz réels et avec la loi des gaz parfaits présentent une déviation de plus de $10 \%$. Cette déviation augmente lorsque la température d'entrée diminue, quelle que soit la pression en entrée. Une contre-pression plus élevée déplace l'onde de choc en amont. Le premier seuil à dépasser pour un fonctionnement normal du séparateur est obtenu pour un ratio de pression de 0,72 . Un second seuil correspond à un ratio de pression de 0,95 , le flux étant cependant dans ce cas subsonique, sans atteindre les conditions de saturation. Dans le cas des modèles de gaz réels, l'onde de choc est décalée vers l'amont par rapport à la loi des gaz parfaits dans la section de séparation cyclonique.
\end{abstract}

\begin{abstract}
Prediction of Mass Flow Rate in Supersonic Natural Gas Processing - The mass flow rate of natural gas through the supersonic separator was numerically calculated by various cubic equations of state. The numerical results show that the compressibility factor and specific heat ratio for ideal gas law diverge remarkably from real gas models at a high inlet pressure. Simultaneously, the deviation of mass flow calculated by the ideal and real gas models reaches over 10\%. The difference increases with the lower of the inlet temperature regardless of the inlet pressure. A higher back pressure results in an earlier location of the shock wave. The pressure ratio of 0.72 is the first threshold to get the separator work normally. The second threshold is 0.95 , in which case the whole flow is subsonic and cannot reach the choked state. The shock position moves upstream with the real gas model compared to the ideal gas law in the cyclonic separation section.
\end{abstract}




\section{INTRODUCTION}

A supersonic separator has been introduced for the natural gas processing, and its typical application is to remove the water vapor from natural gas for the control of the dew point $[1,2]$. In this method, the natural gas liquids and heavier hydrocarbons may also be separated from natural gas depending on the low pressure and temperature resulted by the supersonic expansion. This revolutionary technique combines the theories of fluid mechanics, thermodynamics and phase transformation dynamics to emplace the processes of the gas expansion in supersonic velocities, cyclonic gas/liquids separation and re-compression in a compact tube. The supersonic separator enables high reliability and availability because there are no rotating parts in it. This new separation process prevents the hydrate formation and eliminates the needs for inhibitor and regeneration systems due to the short residence time in the device.

A supersonic separator mainly consists of four parts, namely, a swirling device, a Laval nozzle, a cyclonic separation section and a diffuser. The swirl device is used to transform part of the axial velocity to angular velocity to generate swirls. The Laval nozzle accelerates the natural gas flows, and the sonic speed is obtained at the nozzle throat. In the divergent part, the natural gas is further expanded to supersonic velocity resulting in a low pressure and temperature, which is the foundation condition for the condensation of water vapor. The cyclonic separation section is the extending of the Laval nozzle. It provides enough space and time conditions for the separation processing in supersonic velocities. In the diffuser, the supersonic velocity is changed to subsonic one when the natural gas flow meets the shock wave. Hence, the diffuser transforms the remaining kinetic energy to pressure for energy saving.

The supersonic separation technology has been extensively studied in the past. Alfyorov et al. [3] investigate the separation characteristics of the supersonic separator compared to the Joule-Thomson valve and turbo-expander for natural gas. Liu et al. [4] introduce an indoor supersonic separation rig and test its dehydration performance with moist air for the working fluids. Jassim et al. $[5,6]$ employe a computational fluid dynamics method to investigate the effects of the nozzle geometry and vorticity on the supersonic flow in Laval nozzle. Karimi and Abdi [7] analyze the influences of the gas dynamic parameters on the natural gas flow in the supersonic nozzle, such as the inlet pressure, the inlet temperature, and so on. Malyshkina [8,9] obtaines the distribution of gas dynamic parameters of natural gas through a supersonic separator with a computational method, and a procedure is developed to predict the separation capability of water vapor and higher hydrocarbons from natural gas using a supersonic separator determined by the initial parameters. Zaporozhets et al. [10] introduce an expander-compressor unit namely the thermal gasdynamic separator. In essence, it is a supersonic separator as it consists of a swirler, a nozzle, a separation part and a diffuser. Jiang et al. [11] employe the corrected Internally Consistent Classical Theory and Gyarmathy theory to modeling the nucleation and droplet growth of natural gas in the supersonic separation process. In our previous studies, we design a new supersonic separator incorporating a central body and analyze the effect of the nozzle geometry and swirls on the flow field $[12,13]$. The Reynolds stress model is employed to predict the strong swirling flow of natural gas in the diffusers using the Navier-Stokes equations [14]. The discrete particle method is used to predict the particle separation characteristics in a supersonic separator and the separation efficiency is obtained [15].

As a novel technique for natural gas separation, the supersonic separator has a lot of advantages, such as impact design, low weight, no chemicals and unmanned operation. However, there is a non-negligible weakness, which the device is very sensitive to the inlet gas flow rate due to the presence of a Laval nozzle inside the device. The critical area at the nozzle throat determines the gas mass flow rate through this device. If the mass flow rate is less than the designed one, the natural gas is the subsonic flows in the whole supersonic separator, which cannot reach the required low pressure and temperature for the condensation of the water vapour, which means that it doesn't work in this condition. Therefore, it is important to study and evaluate the gas flow rate through a supersonic separator. The purpose of this study is to employ various cubic Equations Of State (EOS) to evaluate the gas properties and real mass flow rate of natural gas through the supersonic separator. The key pressure ratio will be discussed by analyzing its influence on the shock wave position.

\section{COMPUTATIONAL APPROACH}

\subsection{Governing Equations}

The high pressure natural gas through a supersonic separator reaches supersonic velocities where the Mach number is greater than unity. In the computational fluid dynamics simulation, the governing equations include the compressible conservation of mass (continuity equation), momentum, and energy equations. In this case, we didn't solve the partial differential equations for fully three-dimensional flows. Instead, the 
two-dimensional axisymmetric flows were solved in ANSYS FLUENT platform [16].

\subsection{Real Gas Equations of State}

An Equation Of State (EOS) is usually used to evaluate the fluid properties. The ideal gas law can be employed to describe the mathematical relationship of the Pressure-Volume-Temperature (PVT) of a gas at low pressure and high temperature. Errors in pressure and temperature evaluation lead to the poor prediction of the flow structures. Therefore, a real gas EOS is expected to calculate the thermodynamic parameters of a gas at higher pressures and lower temperatures.

In 1873, van der Waals presented an EOS with the valuable significance. Even though the equation is not accurate for most applications, it provides a perspective for researchers to represent the PVT behavior of gases. Since then, many EOS have been proposed to improve the accuracy in the predictions of thermodynamic properties by modifying the van der Waals EOS. In 1949, Redlich and Kwong [17] propose an Equation Of State (RK EOS) by correcting the attractive term. It has been recognized a most successful modification of the van der Waals EOS and proved its accuracy for many gaseous systems. The RK EOS can be expressed as the following form:

$$
\begin{gathered}
p=\frac{R T}{V-b}-\frac{a}{\left(T / T_{c}\right)^{0.5} V(V+b)} \\
a=0.42747 R^{2} T_{c}^{2} / p_{c} \\
b=0.08664 R T_{c} / p_{c}
\end{gathered}
$$

where $V$ is the gas volume; $R$ is the gas constant; $T_{c}$ and $p_{c}$ are the critical temperature and pressure, respectively.

The success of RK EOS has inspired many researchers for further studies to improve the accuracy. Soave [18] suggests to redefine the term of $\left(T / T_{c}\right)^{-0.5}$ to $a(T)$ function depending on the temperature as follows:

$$
\begin{gathered}
a(T)=\left[1+m\left(1-\left(T / T_{c}\right)^{0.5}\right)\right]^{2} \\
m=0.480+1.574 \omega-0.176 \omega^{2}
\end{gathered}
$$

where $\omega$ is the acentric factor.

After Soave's proposal, some other modifications were proposed for high accuracy. And the most famous of the studies is the Peng-Robinson EOS [19]. Based on the Soave's suggestion, they use the same $a(T)$ function with a different $m$ and modified the volume dependency of the attractive term. PR EOS can be described in Equation (6):

$$
\begin{gathered}
p=\frac{R T}{V-b}-\frac{a a(T)}{V(V+b)+b(V-b)} \\
a=0.457247 R^{2} T_{c}^{2} / p_{c} \\
b=0.07780 R T_{c} / p_{c} \\
m=0.37464+1.54226 \omega-0.2699 \omega^{2}
\end{gathered}
$$

In 1995, Aungier [20] employes the critical point compressibility factor as the additional parameter and redefined the $a(T)$ function to modify the RK EOS. The Aungier EOS form differs from the original RK EOS by a non-zero parameter $c$ which is added to improve the behavior of isotherms near the critical point, as well as setting the exponent $n$ differently. Aungier EOS is expressed as the following form:

$$
\begin{gathered}
p=\frac{R T}{V-b+c}-\frac{a a(T)}{V(V+b)} \\
c=\frac{R T_{c}}{p_{c}+a / V_{c}\left(V_{c}+b\right)}+b-V_{c} \\
a(T)=\left(T / T_{c}\right)^{-m} \\
m=0.4986+1.1735 \omega+0.4754 \omega^{2}
\end{gathered}
$$

where $V_{c}$ is the critical volume. $a$ and $b$ are given by Equation (2) and (3), respectively.

The $R K, S R K, A R K, P R$ equations are widely used in oil and gas industry. The advantages of these equations are that they are easy to use and they often accurately represent the relation between temperature, pressure, and phase compositions in binary and multicomponent systems. These equations only require the critical properties and acentric factor for the generalized parameters. Little computer resources are required and those lead to good phase equilibrium correlation.

For the multi-component mixtures, such as natural gas, mixing laws are utilized to calculate the parameters $a$ and $b$. The van der Waals mixing rules [21, 22] were applied to obtain the EOS parameters for the mixtures from those pure components. The mathematical expressions of this mixing rule can be written:

$$
a=\sum_{i=1}^{n} \sum_{j=1}^{n} x_{i} x_{j} \sqrt{a_{i} a_{j}}\left(1-k_{i j}\right)
$$




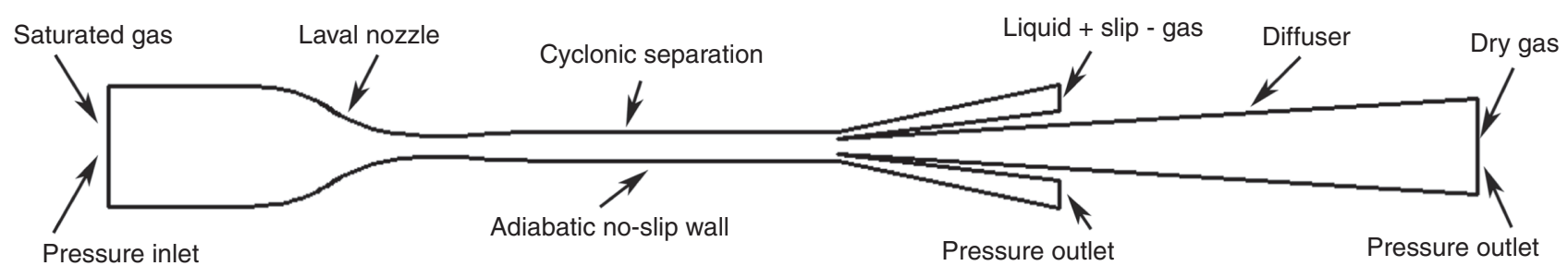

Figure 1

Schematic diagram of the supersonic separator.

$$
b=\sum_{i=1}^{n} x_{i} b_{i}
$$

where $x$ is molar fraction; $n$ is the total number of the gas components; $k_{i j}$ is the binary interaction parameter between components $i$ and $j$.

\subsection{Computational Conditions}

The supersonic separator employed in the computational study consisted of a Laval nozzle, a cyclonic separation section and a diffuser, as shown in Figure 1. The inlet and outlet diameters of the nozzle are $100.00 \mathrm{~mm}$ and $23.83 \mathrm{~mm}$, respectively. The throat diameter is $17.40 \mathrm{~mm}$. The profile of the convergent section of the nozzle is calculated by Equation (16), while the Foelsch's analytical calculation was employed to design the divergent section of the nozzle [23, 24]. The convergence and divergence half angle of the nozzle is $12.48^{\circ}$ and $2.43^{\circ}$, respectively. The diffuser is designed as a straight conic one with the divergence angle of $6^{\circ}$. A constant area tube is inserted between the nozzle and diffuser representing as a cyclonic separation section. In addition, a straight tube with the length of $100 \mathrm{~mm}$ was connected to the upstream and downstream of the device for the computational calculation:

$$
\left\{\begin{array}{cc}
\frac{D-D_{c r}}{D_{1}-D_{c r}}=1-\frac{1}{X_{m}^{2}}\left(\frac{x}{L}\right)^{3} & \left(\frac{x}{L} \leq X_{m}\right) \\
\frac{D-D_{c r}}{D_{1}-D_{c r}}=\frac{1}{\left(1-X_{m}\right)^{2}}\left(1-\frac{x}{L}\right)^{3} & \left(\frac{x}{L}>X_{m}\right)
\end{array}\right.
$$

where $D_{1}, D_{c r}$ and $L$ are the inlet diameter, the throat diameter and the convergent length, respectively. $X_{m}=0.3-0.7 \times x$ is the distance between arbitrary cross section and the inlet, and $D$ is the convergent diameter at arbitrary cross section of $x$.

In this simulation case, the swirling and condensation flows were not considered in the prediction of the gas mass flow rates. Instead, we just considered the single gas flow in a supersonic separator. As a result of the high
Reynolds number in the supersonic separator, the modeling of the turbulence plays a crucial role in the flow prediction [25]. For this sort of flow situation, the pressure gradient is not very large in the gas expansion, while the boundary layers are probably small, and the turbulent boundary layers act just as a correction. The $k-\varepsilon$ model is a two equation model, and it is promisingly accurate for the flows with relatively small pressure gradients and for wall-bounded and internal flows where mean pressure gradients are very small. Hence, the standard $k-\varepsilon$ model is used in this case because of its robustness, economy and reasonable accuracy.

The finite volume methods are employed to solve the governing equations with ANSYS FLUENT being the numerical platform. The semi-implicit method for pressure linked equations (SIMPLE) is adopted for the solution of the momentum equation by guessing the pressure gradient and getting a convergence [26, 27]. The boundary conditions employed in the present computation are shown as follows: pressure inlet for the separator entrance, pressure outlet condition for the exits of dry gas and liquids, respectively. No-slip and adiabatic boundary conditions are supposed for the solid walls. The convergence criterion is $10^{-6}$ for the energy equation and $10^{-3}$ for all other equations.

The natural gas used in the simulation is composed of methane, ethane, propane and water vapour. The mole composition of natural gas is as follows: $95.94 \% \mathrm{CH}_{4}$, $3.00 \% \mathrm{C}_{2} \mathrm{H}_{6}, 1.00 \% \mathrm{C}_{3} \mathrm{H}_{8}, 0.06 \% \mathrm{H}_{2} \mathrm{O}$. The parameters are used in the simulation including the molecular weight, standard state entropy, critical temperature, critical pressure, critical specific volume, acentric factor, and so on.

\section{RESULTS AND DISCUSSION}

\subsection{Validation of Computational Approach}

The model validation work has been performed in a Laval nozzle and reported in our previous publication. 


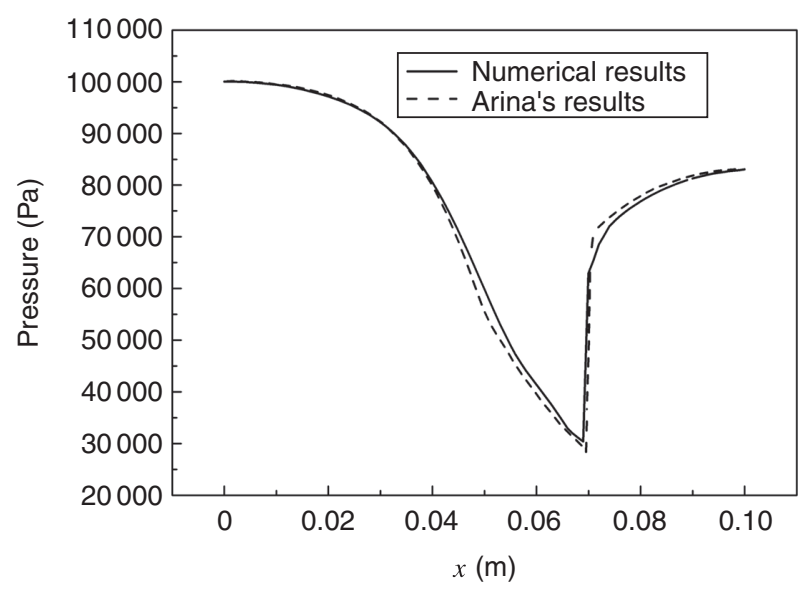

Figure 2

Pressure profiles for nozzle flow.

Detailed information can be found in [28]. Here, only one figure is re-plotted for general understanding. The comparisons of the static pressure in the central line of the Laval nozzle are shown in Figure 2. It can be seen that the same flow behavior is obtained and the shockwave position is accurately captured by our simulation method. Therefore, our computational approach can predict the supersonic flow very well.

\subsection{Ideal Mass Flow Rate of Natural Gas}

The supersonic separator involves a Laval nozzle to expand the natural gas to supersonic velocities for lower pressure and temperature, which is the essential condition for the natural gas separation. Therefore, the mass flow rate to get the supersonic separator work is the choked mass flow rate, $m_{c}$ :

$$
m_{c}=\rho_{c} v_{c} A_{c}=\rho_{c} a_{c} A_{c}
$$

where $v_{c}$ and $a_{c}$ are the gas velocity and sound speed at the nozzle throat, respectively. $\rho_{c}$ is the gas density of the choked flow, and $A_{c}$ is the section area at throat.

Assume that the natural gas follows the ideal gas law, we can obtain the mathematical relationship between the stagnation parameters and choked flow parameters as follows:

$$
\begin{gathered}
p_{0}=\rho_{0} R T_{0} \\
T_{0}=\left(1+\frac{\gamma-1}{2}\right) T_{c}
\end{gathered}
$$

$$
\begin{gathered}
\rho_{0}=\left(1+\frac{\gamma-1}{2}\right)^{\left(\frac{1}{\gamma-1}\right)} \rho_{c} \\
a_{c}=\sqrt{\gamma R T_{c}}
\end{gathered}
$$

where $\gamma$ is the specific heat ratio. $p_{0}, \rho_{0}$ and $T_{0}$ are the stagnation parameters, respectively.

Substituting relationships (18-21) into Equation (17), and the choked mass flow rate can be expressed as:

$$
m_{c}=\sqrt{\gamma}\left(\frac{2}{\gamma+1}\right)^{\frac{\gamma+1}{2(\gamma-1)}} \frac{p_{0}}{\sqrt{R T_{0}}} A_{c}
$$

To evaluate the real gas effects on the mass flow rate of natural gas through the supersonic separator, we define a dimensionless parameter deviation factor of the mass flow rate, $m_{e}$ :

$$
m_{e}=\frac{m_{r}-m_{c}}{m_{c}} \times 100 \%
$$

where $m_{r}$ is the mass flow rate calculated by the real gas models.

\subsection{Mass Flow Rate with Real Gas Models}

The mass flow rate of natural gas through the supersonic separator is computationally simulated using various real gas models (RK, RKS, PR and RKA EOS in present simulations), respectively. The compressibility factor is the ratio of the molar volume of a gas to the molar volume of an ideal gas at the same temperature and pressure. It is a useful thermodynamic property for modifying the ideal gas law to account for the real gas behavior. The compressibility factor, $Z$, is defined as:

$$
Z=p V / R T
$$

where $V$ is the molar volume, $p$ is the pressure, $T$ is the temperature, and $R$ is the gas constant. The compressibility factor, $Z$, will be 1 for an ideal gas.

The compressibility factor was employed to assess the real gas effects with the inlet pressure of $5 \mathrm{~atm}$ and $60 \mathrm{~atm}$, as shown in Figure 3. One can see that the natural gas has a compressibility factor of 0.99 in the whole supersonic separator with a lower inlet pressure (5 atm), which means the natural gas has a little difference from the ideal gas. On the contrary, when the inlet pressure is about $60 \mathrm{~atm}$, the compressibility factor greatly increases in the Laval nozzle, and keeps nearly a constant in the cyclonic separation section. Then, the compressibility factor sharply declines as a result of the emergency of the shock. In the whole separation 


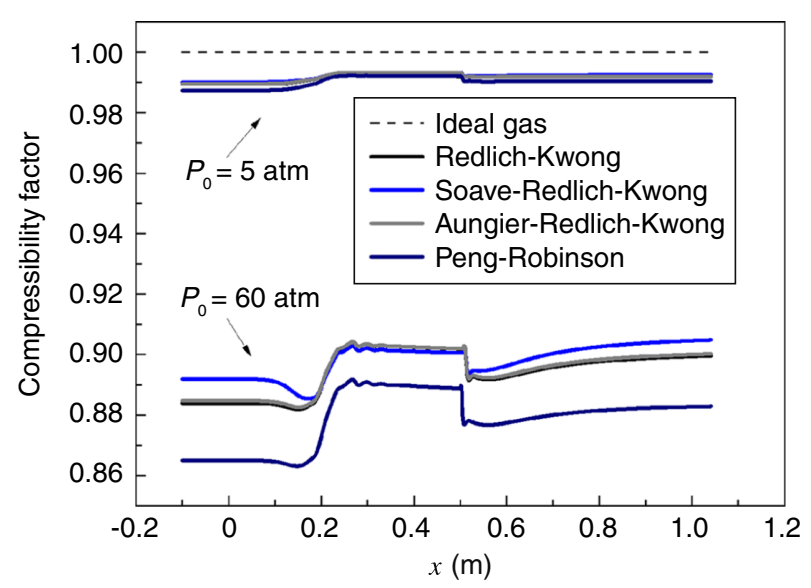

Figure 3

Compressibility factors of natural gas at the inlet pressure of $5 \mathrm{~atm}$ and $60 \mathrm{~atm}$.

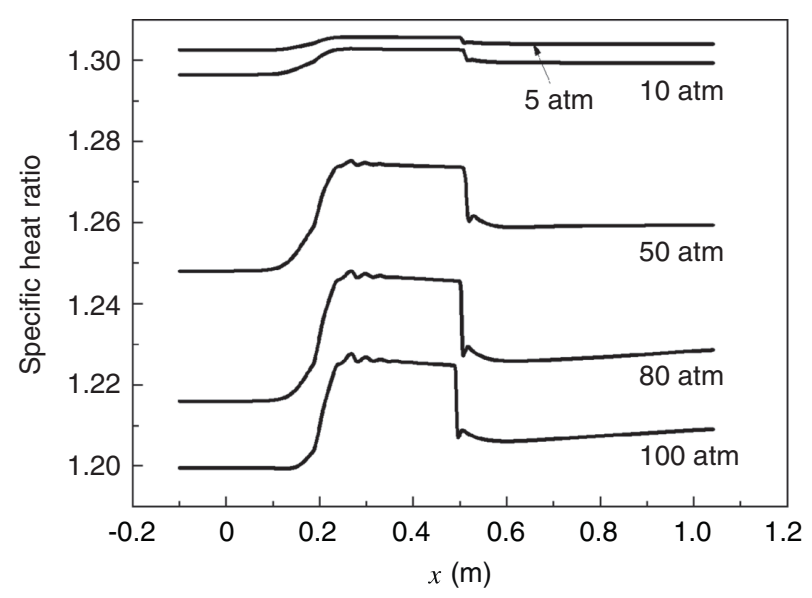

Figure 4

Specific heat ratio along the axis at various inlet pressures.

processing of natural gas in the supersonic separator, the compressibility factor diverges from the ideal value of unity, although the results calculated by the RK, RKS, PR and RKA EOS have a little difference from one to the other. Therefore, it can be concluded that the compressibility factor of natural gas affects the evaluation of the mass flow rate compared to the ideal gas through the supersonic separator at a high pressure.

Equation (22) indicates that the specific heat ratio plays an important role in the prediction of the mass flow rate of natural gas through a supersonic separator. Therefore, the specific heat ratio of natural gas is computationally calculated by PR EOS at various inlet pressures, and the axial profiles are depicted in Figure 4. The ideal ratio of specific heat of natural gas is constant

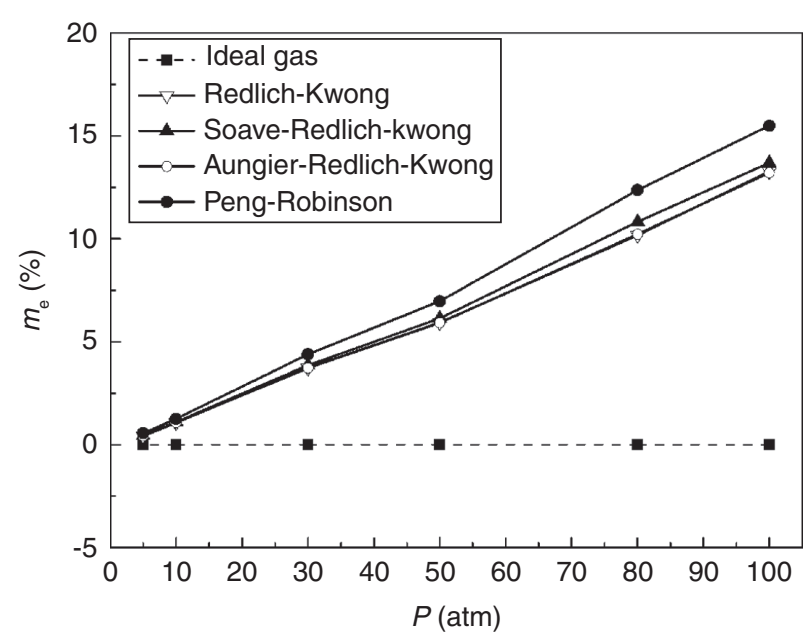

Figure 5

Deviation factor of mass flow of natural gas with real gas models.

at 1.304. One can see that the specific heat ratio rises suddenly in the Laval nozzle due to the acceleration of natural gas with an abrupt drop in the shock position, when the PR real gas model is performed. A similar tendency appears at various inlet pressures, but the amplitude of variation of the profiles of the specific heat ratio rises with higher inlet pressure. Moreover, the specific heat ratio decreases with the increase of the inlet pressure at a fixed position. That is, these variations at the nozzle throat affect significantly the calculation of the mass flow rate of natural gas through the supersonic separator.

Figure 5 shows the divergence of the mass flow rate of natural gas calculated by the ideal gas law and the real gas models. The inlet temperature was fixed at $288 \mathrm{~K}$ to evaluate the effect on the mass flow rate. It can be seen that the deviation factor, $m_{e}$ increases with a higher inlet pressure for the real gas models. When the inlet pressure is less than $50 \mathrm{~atm}$, the deviation factor is below $5 \%$. If the inlet pressure becomes higher than $80 \mathrm{~atm}$, the factor $m_{e}$ will be more than $10 \%$. In the operation of the supersonic separator, it usually works at a high inlet pressure, such as $100 \mathrm{~atm}$ or a little more. In this condition, the real gas model should be taken into account for the mass flow rate of natural gas through the supersonic separator.

\subsection{Effects of Inlet Temperature on Mass Flow Rate}

The ideal gas law and Peng-Robinson EOS are employed to predict the effects of inlet temperature on the mass flow rate of natural gas. Figure 6 depicts the profiles of the deviation factor at various inlet temperatures with 


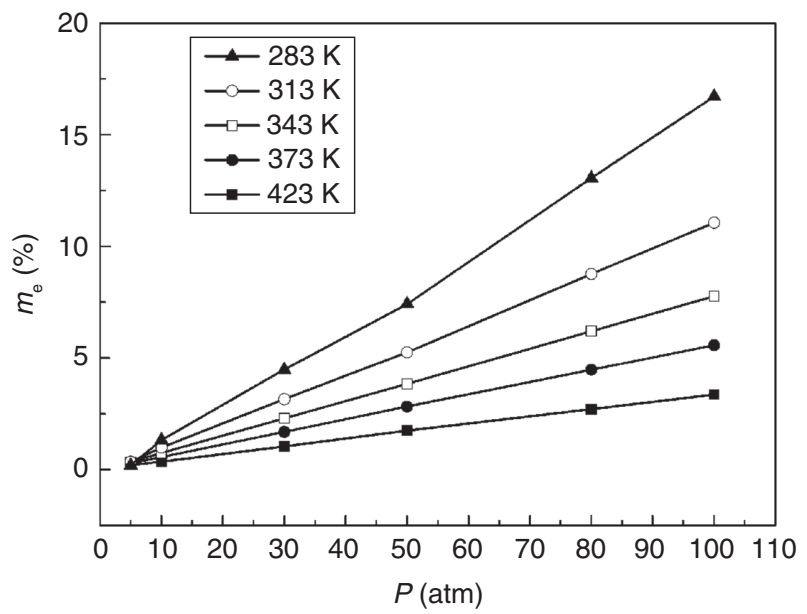

Figure 6

Effect of inlet temperature on the mass flow rate with PR EOS model.

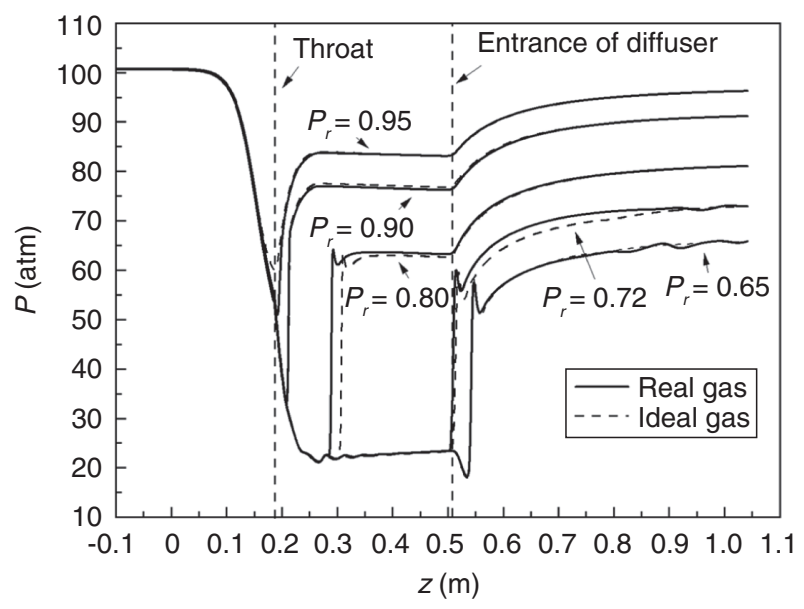

Figure 7

Distribution of the static pressure with different back pressures. the inlet pressure from $5 \mathrm{~atm}$ to $100 \mathrm{~atm}$. The deviation factor of natural gas rises with the decrease of the inlet temperature regardless of the inlet pressure. The growth rate of the deviation factor becomes larger at a higher inlet pressure. At a low inlet pressure, less than $30 \mathrm{~atm}$, for example, the factor is below $5 \%$ even with a low temperature of $283 \mathrm{~K}$. However, there would be a huge deviation of mass flow rate of natural gas if the ideal gas law was used to calculate the thermodynamic properties at the high pressure and low temperature. For instance, the calculation error reaches about $16.5 \%$ at the inlet pressure of $100 \mathrm{~atm}$ with the temperature of $283 \mathrm{~K}$. Therefore, the ideal gas law will result in an error on the prediction of mass flow rate of natural gas through the supersonic separator. In the gas field, the typical operating condition for a supersonic separator is that the inlet temperature is normally less than $303 \mathrm{~K}$ with the inlet pressure of about $100 \mathrm{~atm}$. In these conditions, the real gas model should be employed to predict the gas flow rate through a supersonic separator. Otherwise, the designed gas mass flow rate will be lower than $10 \%$ of the real one, if the ideal gas law is used. It causes that the natural gas flow can't be choked at the nozzle throat. That is, the gas flow is subsonic in the whole supersonic separator, which can't induce the low pressure and temperature for nucleation and condensation of a water vapour.

\subsection{Pressure Ratio and Mass Flow Rate}

The static pressure of natural gas along the supersonic separator axis is shown in Figure 7 at the different pressure ratio $p_{r}$, which is the ratio of the back pressure to the inlet one. The back pressure is the one at the separator outlet. The shock wave moves upstream with the increase of the pressure ratio from the diffuser to the nozzle. The shock wave can stay in the diffuser when the pressure ratio keeps below 0.72 . If the pressure ratio becomes a little bigger, the shock wave will go into the cyclonic separation section, resulting in a sudden rise of the static pressure, which will destroy the supersonic separation processing. Thus, the pressure ratio of 0.72 is the first threshold to make the supersonic separator workable. When the pressure ratio reaches 0.95 , the shock goes across the throat and the whole flow is subsonic through the supersonic separation. This is the second threshold of the pressure ratio, in which the mass flow rate cannot reach the choked flow. In the nozzle and the diffuser, both the ideal gas law and PR real gas predict the same distributions of the static pressure. In the cyclonic separation section, the real gas model predicts an earlier shock location compared to the ideal gas law. It means that the shock position is sensitive to the pressure ratio with the real gas model.

Moreover, the RK real gas model is employed to predict the vital pressure ratio representing the RK EOS, since they nearly predicted the similar results as shown in Figures 3 and 5. The data also show a similar result in the aspect of predicting the pressure ratio compared to the PR model. This indicates that the threshold of the pressure ratios predicted by the real gas model can be used in the design of a supersonic separator. 


\section{CONCLUSIONS}

The mass flow rate of natural gas through the supersonic separator was predicted using the ideal gas law and cubic equations of state. At a high pressure, the compressibility factor calculated by the real gas models diverged significantly from the results of ideal gas, showing the real gas effects on the supersonic separation processing. In the PR real gas model, the specific heat ratio rised in the Laval nozzle and dropped sharply at the shock wave location. The variation of the specific heat ratio at the nozzle throat had an important effect on the evaluation of the mass flow rate of natural gas. The computational study indicated that the deviation of the mass flow rate of the ideal gas reached over $10 \%$ compared to the real gas models at higher pressure.

The deviation of mass flow rate of natural gas increased with the decline of the inlet temperature regardless of the inlet pressure, when the ideal and real gas models were used for the simulation. The calculation error of mass flow rate reached $16.5 \%$ in a higher inlet pressure and lower inlet temperature $\left(100 \mathrm{~atm}, 15^{\circ} \mathrm{C}\right)$.

The position of the shock wave moved upstream from the diffuser to the nozzle with the increase of the back pressure. The first threshold of the back pressure of 0.72 times of the inlet one was found to get the supersonic separator work normally, where the real mass flow rate of natural gas was still the choked one. If the pressure ratio increased to 0.95 , the shock went across the throat and the whole flow was the subsonic through the supersonic separator. This was the second threshold and the mass flow rate could not reach the choked flow.

\section{ACKNOWLEDGMENTS}

This work was supported in part by the National Natural Science Foundation of China (No. 51274232) and the Research Program for Excellent Doctoral Dissertation of China University of Petroleum. C. Wen acknowledges a fellowship from the China Scholarship Council (201206450035).

\section{REFERENCES}

1 Okimoto D., Brouwer J. (2002) Supersonic Gas Conditioning, World Oil 223, 89-91.

2 Betting M., Epsom H. (2007) Supersonic Separator Gains Market Acceptance, World Oil 254, 197-200.

3 Alfyorov V., Bagirov L.A., Dmitriev L., Feygin V., Imayev S., Lacey J.R. (2005) Supersonic Nozzle Efficiently Separates Natural Gas Components, Oil Gas J. 103, 53-58.
4 Liu H., Liu Z., Feng Y., Gu K., Yan T. (2005) Characteristic of a Supersonic Swirling Dehydration System of Natural Gas, Chin. J. Chem. Eng. 1, 9-12.

5 Jassim E., Abdi M.A., Muzychka Y. (2008) Computational Fluid Dynamics Study for Flow of Natural Gas through High-pressure Supersonic Nozzles: Part 1. Real Gas Effects and Shockwave, Pet. Sci. Technol. 26, 1757-1772.

6 Jassim E., Abdi M.A., Muzychka Y. (2008) Computational Fluid Dynamics Study for Flow of Natural Gas through High-pressure Supersonic Nozzles: Part 2. Nozzle Geometry and Vorticity, Pet. Sci. Technol. 26, 1773-1785.

7 Karimi A., Abdi M.A. (2009) Selective Dehydration of High-Pressure Natural Gas Using Supersonic Nozzles, Chem. Eng. Process. 48, 560-568.

8 Malyshkina M.M. (2008) The Structure of Gas Dynamic Flow in a Supersonic Separator of Natural Gas, High Temp. 46, 69-76.

9 Malyshkina M.M. (2010) The Procedure for Investigation of the Efficiency of Purification of Natural Gases in a Supersonic Separator, High Temp. 48, 244-250.

10 Zaporozhets E.P., Zibert G.K., Zibert A.G. (2011) Thermal Gas Dynamic Separator, Chem. Petrol. Eng. 46, 585-593.

11 Jiang D., Eri Q., Wang C., Tang L. (2011) A Fast and Efficient Numerical-Simulation Method for Supersonic Gas Processing, SPE Projects, Facilities \& Construction 6, 58-64.

12 Wen C., Cao X., Yang Y., Zhang J. (2011) Supersonic Swirling Characteristics of Natural Gas in ConvergentDivergent Nozzles, Petrol. Sci. 8, 114-119.

13 Wen C., Cao X., Yang Y., Zhang J. (2011) Swirling Effects on the Performance of Supersonic Separators for Natural Gas Separation, Chem. Eng. Technol. 34, 1575-1580.

14 Wen C., Cao X., Yang Y., Li W. (2012) Numerical Simulation of Natural Gas Flows in Diffusers for Supersonic Separators, Energy 37, 195-200.

15 Wen C., Cao X., Yang Y., Zhang J. (2012) Evaluation of Natural Gas Dehydration in Supersonic Swirling Separators Applying the Discrete Particle Method, Adv. Powder Technol. 23, 228-233.

16 ANSYS Fluent User Manual, 2011, ANSYS INC.

17 Redlich O., Kwong J.N.S. (1949) On the Thermodynamics of Solutions. V. An Equation of State. Fugacities of Gaseous Solutions, Chem. Rev. 44, 233-244.

18 Soave G. (1972) Equilibrium Constants from a Modified Redlich-Kwong Equation of State, Chem. Eng. Sci. 27, 1197-1203.

19 Peng D.Y., Robinson D.B. (1976) A New Two-Constant Equation of State, Ind. Eng. Chem. Fundam. 15, 59-64.

20 Aungier R.H. (1995) A Fast, Accurate Real Gas Equation of State for Fluid Dynamic Analysis Applications, J. Fluids Eng. 117, 277-281.

21 Kwak T.Y., Mansoori G.A. (1986) Van der Waals Mixing Rules for Cubic Equations of State. Applications for Supercritical Fluid Extraction Modeling, Chem. Eng. Sci. 41, 1303-1309.

22 Benmekki E.H., Kwak T.Y., Mansoori G.A. (1987) Supercritical Fluids, American Chemical Society, Washington.

23 Wen C., Cao X., Yang Y. (2011) Swirling Flow of Natural Gas in Supersonic Separators, Chem. Eng. Process. 50, 644-649. 
24 Foelsch K. (1949) The Analytical Design of an Axially Symmetric Laval Nozzle for a Parallel and Uniform Jet, J. Aero. Sci. 16, 161-166.

25 Pope S.B. (2000) Turbulent flows, Cambridge University Press, Cambridge.

26 Patankar S.V., Spalding D.B. (1972) A Calculation Procedure for Heat, Mass and Momentum Transfer in ThreeDimensional Parabolic Flows, Int. J. Heat Mass Trans. 15, 1787-1806.
27 Patankar S.V. (1980) Numerical Heat Transfer and Fluid Flow, McGraw-Hill, New York.

28 Wen C., Cao X., Yang Y., Li W. (2011) An Unconventional Supersonic Liquefied Technology for Natural Gas, Energy Educ. Sci. Technol. 30, 651-660.

Manuscript accepted in October 2013

Published online in December 2013

Cite this article as: C. Wen, X. Cao, Y. Yang and Y. Feng (2013). Prediction of Mass Flow Rate in Supersonic Natural Gas Processing, Oil Gas Sci. Technol 70, 6, 1101-1109. 